\title{
Influence of Braking Strategies for Electric Trike Energy Consumption
}

\author{
Metha Islameka $^{1}$, Christopher Fernaldy Kusuma ${ }^{2}$, Bentang Arief Budiman ${ }^{3 *}$ \\ ${ }^{1}$ Faculty of Industrial Engineering, Institut Teknologi Bandung, Ganesha Street No. 10, Bandung, 40132, Indonesia \\ ${ }^{2}$ Product Planning Division, PT. Astra Daihatsu Motor, Surya Pratama Street Blok I Kav. 47-57, Karawang, 41363, \\ Indonesia \\ ${ }^{3}$ Faculty of Mechanical and Aerospace Engineering, Institut Teknologi Bandung, Ganesha Street No. 10, Bandung, \\ 40132, Indonesia \\ *Email: bentang@ftmd.itb.ac.id
}

\begin{abstract}
This research aims to investigate the effect of applying braking strategies to the energy consumption of electric trike (e-trike). E-trike is a three-wheeled vehicle that is designed for goods delivery. A simulation is carried out to find the specific electric energy consumption in terms of $\mathrm{km} / \mathrm{kWh}$. The simulation is conducted by developing an energy consumption model using Matlab/Simulink software. The input data used in the simulation is obtained from the etrike specification designed by Institut Teknologi Bandung (ITB) researchers. The output is the battery State of Charge (SOC) and energy required for the Worldwide Harmonized Light Vehicle Test Procedure (WLTP) driving cycle. Four different braking strategies are implemented in the simulation, namely full mechanical braking, serial regenerative braking, parallel regenerative braking, and modified braking strategies. The simulation results show that by applying the modified braking strategy, greater savings of energy can be achieved. Full mechanical braking strategy can achieve energy savings of $19.2 \mathrm{~km} / \mathrm{kWh}$ whereas the modified braking strategy generates $20 \mathrm{~km} / \mathrm{kWh}$. These results indicate that the application of modified braking strategies can significantly increase the e-trike mileage.
\end{abstract}

\section{Keywords}

Braking strategies; Regenerative braking; Electric trike; Energy consumption

\section{Introduction}

An electric trike (e-trike) is a three-wheeled vehicle that uses electricity for propulsion needs. One of the benefits of the e-trike is the ability to carry larger sized cargo than motorcycles with sleeker vehicle size and shape compared to small trucks, making it easier to be used on narrow and winding roads $[1,2]$. Ma et al. stated that the maintenance of an electric vehicle is cheaper than vehicles with internal combustion engines [3]. Therefore, the e-trike is also expected to reduce the cost of shipping goods.

Chan stated that one of the advantages of the electric vehicle is zero-emission [4]. Besides, Nyeste and Wogalter have studied that electric vehicles are also able to reduce noise pollution because the electric drive engine does not produce noise [5]. However, several studies stated that the distance that can be traveled by electric vehicles is limited due to the battery capacity, which also has a limitation $[6,7]$. This is due to the energy storage density in the battery, which is still far lower than gasoline fuel [8]. Regenerative braking can be a solution to increase the distance that can be traveled by electric vehicles [9-11]. Keil and Jossen have studied that recharging the electrical energy in the battery during braking can be conducted because it does not increase the degradation of the battery [12]. Heydari et al. stated that the use of regenerative braking still requires mechanical braking because the braking energy produced by regenerative braking is not enough for emergency conditions [13].

In this study, the simulation of the energy consumption of an e-trike is conducted. The simulation is performed by developing an energy consumption model using Matlab/Simulink. Furthermore, the battery State of Charge (SOC) and energy consumption data are produced. Islameka et al. have studied the simulation using four different braking strategies, namely full mechanical braking, serial regenerative braking, parallel regenerative braking, and modified braking strategies for an electric bus [14]. Then, the efficiency of each braking strategy is compared to get the best one. Those four strategies are implemented in the simulation of energy consumption of e-trike. 


\section{Experimental Method}

\subsection{E-trike specification}

Figure 1 shows the goods delivery e-trike designed by ITB researchers, with the general specification shown in Table 1. Gross vehicle weight is the total mass of the vehicle along with the payload, which consists of passengers and cargo mass. This gross vehicle weight value is used to calculate the amount of braking force that is required by the vehicle. The vehicle is designed to travel on asphalt road with a friction coefficient of 0.75 [15]. Additional load power input data is obtained from things which also require constant electrical energy in a vehicle. In this case, it comes from 2 headlights, four turn signals, and two brake lights with a total value of $110 \mathrm{~W}, 72 \mathrm{~W}$, and around $10-42 \mathrm{~W}$, respectively. In braking condition, the required brake light power is 21 watts. When the brakes are not functioning, the brake light power becomes a twilight lamp, which requires 5 watts.

Table 2 shows the specifications of the electric motor. Input torque data used for the simulation is the maximum one. Motor efficiency input data that is employed is assumed constant with a maximum value which can be achieved. Table 3 shows the specifications of the battery used for the e-trike. The battery input data that is employed for the simulation is considered ideal with Lithium Ferrophosphate (LFP) as the typical battery. The resistance value of the LFP battery is 30 $\mathrm{m} \Omega$. The total resistance value of the battery is calculated using the total resistance in the LFP battery pack.

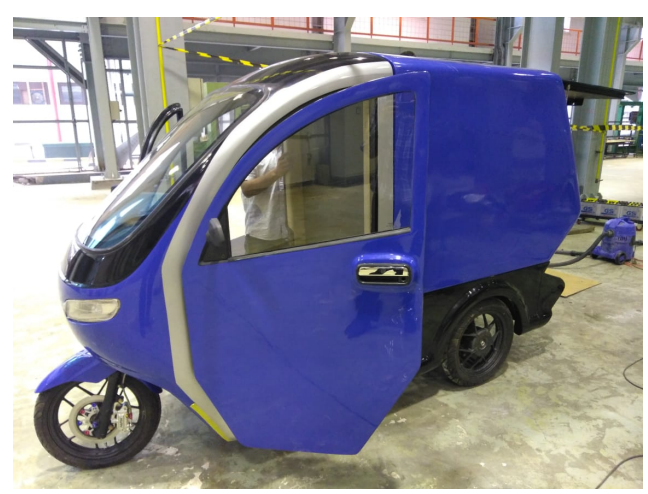

Figure 1 E-trike for goods delivery

Table 1 E-trike specifications

\begin{tabular}{ccccc}
\hline No & Description & Symbol & Value & Unit \\
\hline 1 & Gross Vehicle Weight & $m_{\text {gross }}$ & 500 & $\mathrm{~kg}$ \\
2 & Payload & $m_{\text {payload }}$ & 300 & $\mathrm{~kg}$ \\
3 & Maximum Velocity & $v_{\text {maks }}$ & 40 & $\mathrm{~km} / \mathrm{h}$ \\
4 & Air Density & $\rho$ & 1.275 & $\mathrm{~kg} / \mathrm{m}^{3}$ \\
5 & Aerodynamic Drag & $C_{d}$ & 0.295 & - \\
6 & Coefficient & $\mu$ & 0.75 & - \\
7 & Friction Coefficient & $\mu$ & $192-224$ & $\mathrm{~W}$ \\
\hline
\end{tabular}

Table 2 Electric motor specifications on the e-trike

\begin{tabular}{ccccc}
\hline No & Description & Symbol & Value & Unit \\
\hline 1 & Continuous Torque & $\tau_{\text {motor }}$ & 17 & $\mathrm{Nm}$ \\
2 & Maximum Torque & $\tau_{\text {maxmotor }}$ & 25 & $\mathrm{Nm}$ \\
3 & Motor Power & $P_{\text {motor }}$ & 5000 & $\mathrm{~W}$ \\
4 & Motor Efficiency & $\eta_{\text {motor }}$ & 85 & $\%$ \\
\hline
\end{tabular}

Table 3 Battery specifications on the e-trike

\begin{tabular}{ccccc}
\hline No & Description & Symbol & Value & Unit \\
\hline 1 & Battery Capacity & $E$ & 4.8 & $\mathrm{kWh}$ \\
2 & Electric Charge & $C$ & 67.2 & $\mathrm{Ah}$ \\
3 & Voltage & $V_{o c}$ & 72 & $\mathrm{~V}$ \\
4 & Internal Resistance & $R_{\text {int }}$ & 0.045 & $\Omega$ \\
\hline
\end{tabular}

\subsection{Driving cycles}

The driving cycles used for the simulation are the Worldwide Harmonized Light Vehicle Test Procedure (WLTP) cycle [16]. There are three classes in the WLTP cycle. Each of them is distinguished by the ratio of rated power to curb weight. Figure 2 shows the WLTP cycle class 2 that is used in the simulation. The cycle was chosen because the power to curb the weight ratio of the e-trike is $25 \mathrm{~W} / \mathrm{kg}$. WLTP cycle class 2 consists of three-speed phases, namely low, medium, and high. The high-speed phase in the WLTP cycle is changed to the low-speed phase because the maximum speed of the etrike is below $90 \mathrm{~km} / \mathrm{h}$.

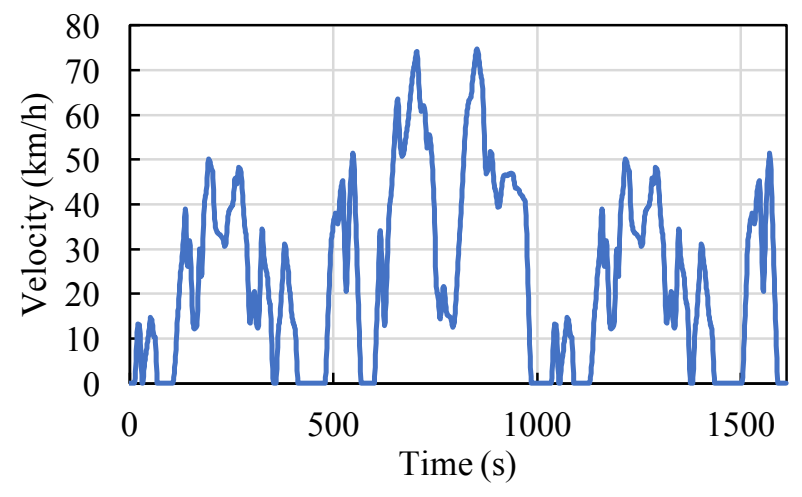

Figure 2 WLTP class 2

\subsection{Energy consumption model}

Figure 3 shows the energy consumption model for electric vehicles [14]. The input data on the energy consumption model are the WLTP driving cycle and etrike specifications. There are five components in the model, namely the driveline, braking strategy, gearbox, electric motor, and battery. The output data from the model are the battery SOC and total energy consumption for one driving cycle.

\section{Driveline component}

The driveline component contains an equilibrium of forces on an electric vehicle based on the d'Alembert principle. Lanczos [17] stated that d'Alembert principle 


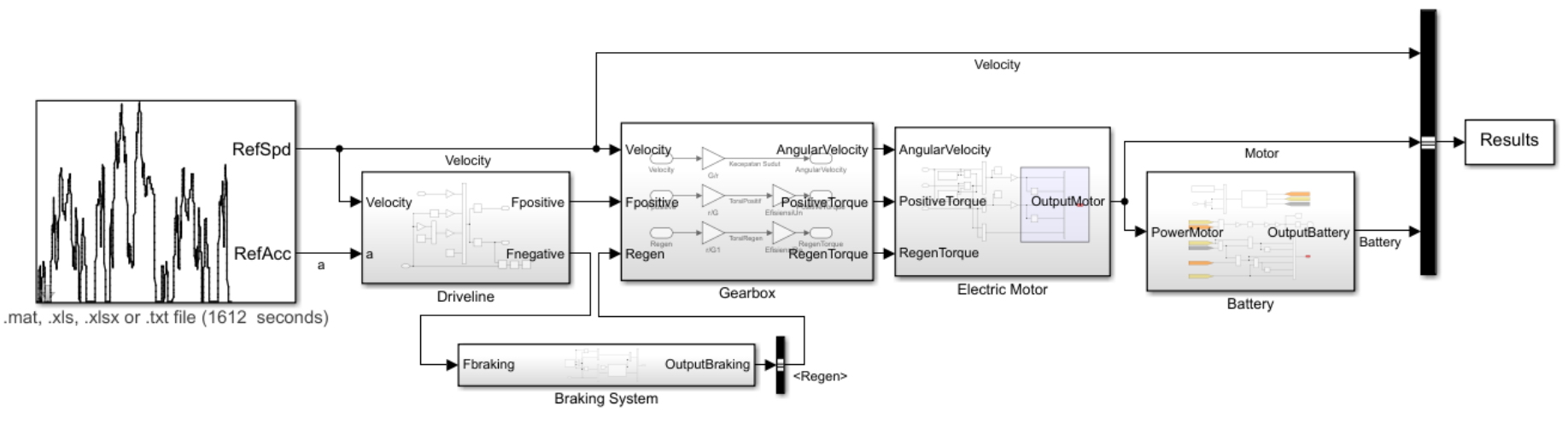

Figure 3 Block diagram of electric vehicle model

introduces the force of inertia, defined as the negative value of the product of mass multiplied by acceleration. Equations (1) and (2) show the calculations that occur in the driveline component, where $F_{t}(t)$ Is the value of traction force occurred on an object at a certain time and $F_{R}(t)$ is a resistance force that is required to be overcome by traction force at a certain time.

$$
\begin{aligned}
& F_{t}(t)-F_{R}(t)=0 \\
& F_{t}(t)=F_{i}(t)+R_{a}(t)+R_{r l}(t)+R_{g}(t)
\end{aligned}
$$

The existing resistance force on an e-trike comes in 4 forms which are: 1) the aerodynamic resistance at a certain time $\left.\left(R_{a}(t)\right), 2\right)$ the resistance of the wheel rotation at a certain time $\left.\left(R_{r l}(t)\right), 3\right)$ the resistance of the road slope at a certain time $\left(R_{g}(t)\right)$, and 4) the style of inertia at a certain time $\left(F_{i}(t)\right)$.

\section{Braking strategy component}

There are four braking strategies to be simulated, namely full mechanical braking strategy, serial regenerative-braking strategy, parallel regenerativebraking strategy, and modified-braking strategy. The total amount of braking force that is required by the vehicle will be divided into the front and rear wheel, which amount is limited by the ideal braking distribution curve. Zhang, Dong, and Han [18] stated that equation (3) and (4) is the formula for the ideal braking distribution curve for the front axle and rear axle, respectively, where $F_{b f}$ and $F_{b r}$ are respectively the braking force on the front axle and rear axle, $\mu$ is the friction coefficient between the wheels and the road, $W$ is the weight of the e-trike, $L$ is the distance between the front and rear axles on an e-trike or wheelbase, $l_{r}$ is the distance between the rear axle and the center of mass from the e-trike, and $h$ is the distance between the center of mass and the surface road.

$$
\begin{aligned}
& F_{b f}=\mu \times\left(\frac{W}{L} \times\left(l_{r}+(\mu \times h)\right)\right) \\
& F_{b r}=\frac{1}{2}\left[\frac{W}{h} \sqrt{l_{r}{ }^{2}+\frac{4 h L}{W} F_{b f}}-\left(\frac{W \times l_{r}}{h}+2 F_{b f}\right)\right]
\end{aligned}
$$

After the required braking force values are obtained, the value is controlled with each serial regenerativebraking, parallel regenerative-braking, and modifiedbraking strategies. Figure 4 shows the differences between the three braking control systems, which are represented in 3 different colors. The green portion indicates the regenerative braking force on the driven axle, the blue portion indicates non-regenerative braking force on the driven axle, and the orange portion indicates non-regenerative braking force on the nondriven axle.

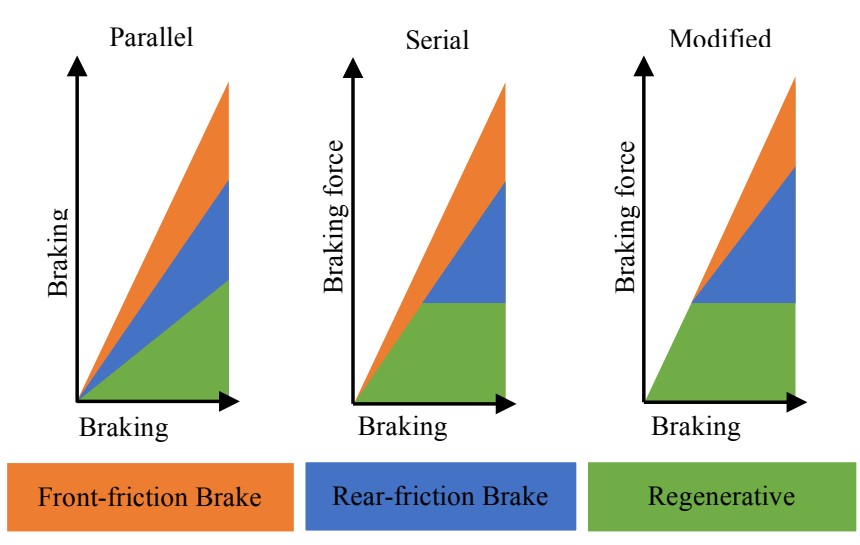

Figure 4 Braking control system

\section{Gearbox component}

The gearbox component contains the translation dynamics conversion to the rotation. Equations (5), (6), and (7) show the calculations that occur in the driveline component. 


$$
\begin{aligned}
& \omega(t)=\frac{G}{r} v(t) \\
& \tau_{t}(t)=\frac{r}{G} F_{t}(t) \\
& \tau_{\text {regen }}(t)=\frac{r}{G} F_{\text {regen }}(t)
\end{aligned}
$$

Where:

$$
\begin{array}{ll}
\omega(t) & \begin{array}{l}
: \text { angular speed of the motor at a certain } \\
\text { time }(\mathrm{rpm})
\end{array} \\
G & \begin{array}{l}
: \text { total gear ratio } \\
: \text { wheel radius }(\mathrm{m})
\end{array} \\
v & \begin{array}{ll}
: \text { speed of the electric bus at a certain time } \\
(\mathrm{m} / \mathrm{s})
\end{array} \\
\tau_{t}(t) & \begin{array}{l}
: \text { motor traction torque at a certain time } \\
(\mathrm{Nm})
\end{array} \\
\tau_{\text {regen }}(t) & \begin{array}{l}
: \text { regenerative torque at a certain time } \\
(\mathrm{Nm})
\end{array} \\
F_{\text {regen }}(t) & : \text { regenerative force at a certain time }(\mathrm{N})
\end{array}
$$

\section{Electric motor component}

The electric motor component also functions as a generator, which calculates the amount of power that is required by the motor during one driving cycle. Equation (8) shows the limit on the allowed electric motor power.

$$
P_{\text {motor }}(t)=\tau(t) \cdot \omega(t)
$$

With restrictions,

$\tau(t)<\tau_{\text {maxmotor }}$

$\tau(t)<\frac{P_{\text {maxmotor }}}{\omega(t)}$

Where,

$P_{\text {motor }}(t)$ : electric motor power at a certain time (W)

$\tau(t) \quad:$ the torque of the electric motor at a certain time $(\mathrm{Nm})$

$\omega(t) \quad:$ the angular speed of the electric motor at a certain time (rpm)

$\tau_{\text {maxmotor }}:$ the maximum torque of the electric motor $(\mathrm{Nm})$

$P_{\text {maxmotor }}:$ maximum power of an electric motor (W)

\section{Battery component}

The battery component converts power into an electric charge and vice versa so that it can calculate the battery SOC. Equation (9) shows the battery SOC calculation, where $S O C(t)$ is the amount of SOC battery at a certain time, $E_{\text {batt }}(t)$ is the amount of battery energy used at a certain time, and $E$ is the capacity of the battery.

$$
\operatorname{SOC}(t)=\frac{E_{\text {batt }}(t)}{E} \times 100
$$

\section{Results and Discussion}

The simulation of the e-trike energy consumption with the WLTP class 2 driving cycle has resulted in the form of a decrease in battery SOC and the amount of consumed energy. Figure 5 shows a decrease in battery SOC of the e-trike with four different braking strategies. The difference in the battery SOC decrease is exhibited after 1290 seconds. Figure 6 shows a greater depiction of the condition of the battery SOC after 1290 seconds.

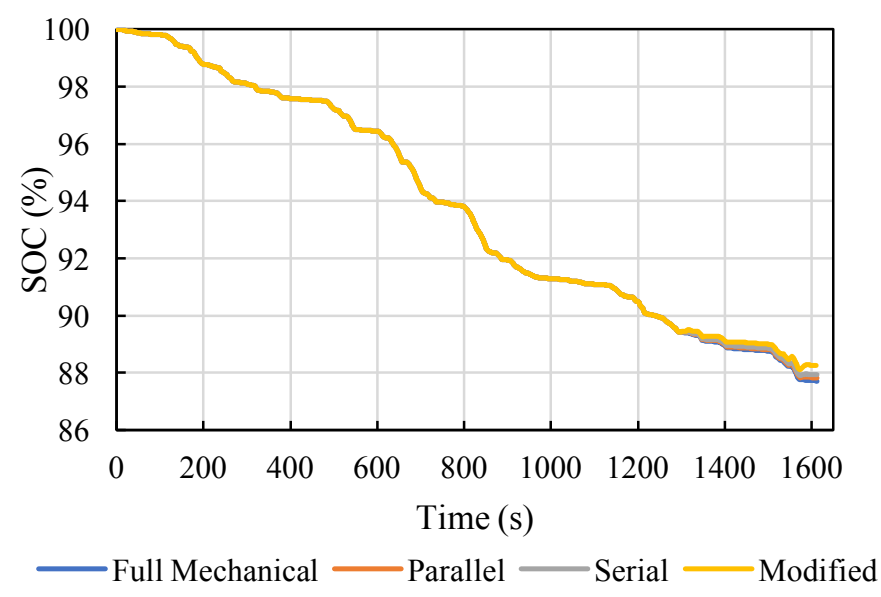

Figure 5 SOC of one driving cycle of four braking strategies

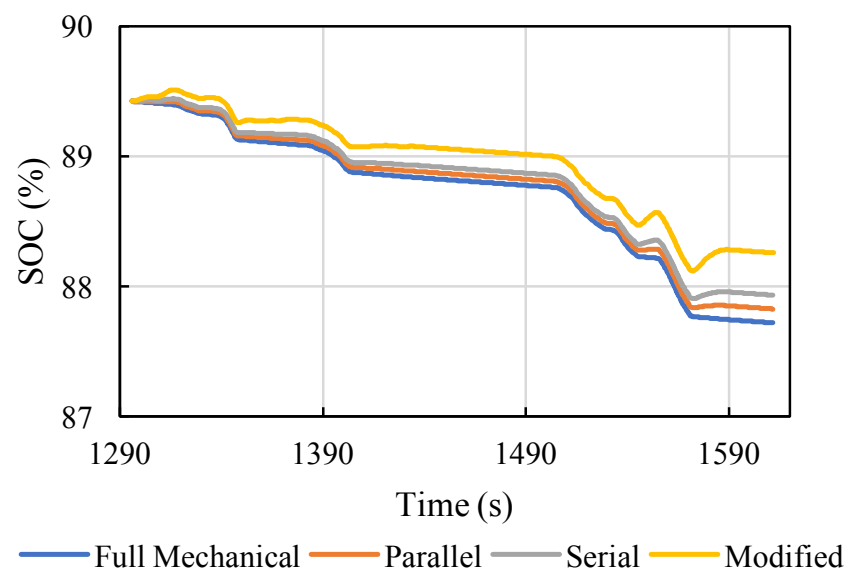

Figure 6 The difference in SOC battery decrease of four braking strategies 
The difference in battery SOC after 1290 seconds is caused by the control system in using the regenerative braking function. Regenerative braking will function when the SOC battery is below $90 \%$. Cao and Ishikawa stated that batteries are very prone to overcharging when regenerative braking is performed above $90 \%$ [19]. Figure 6 also shows the remaining battery SOC from each braking strategy. The remaining battery SOC for full mechanical braking, parallel regenerative braking, serial regenerative braking, and modified braking strategies is $87.7 \%, 87.8 \%, 87.9 \%$, and $88.3 \%$, respectively.

Figure 7 shows the value of energy consumption of one WLTP driving cycle with four different braking strategies. Figure 8 shows the difference in energy consumption of the four braking strategies. The difference of the consumed energy values of the four braking strategies is $0.572 \mathrm{kWh}, 0.567 \mathrm{kWh}, 0.56 \mathrm{kWh}$, and $0.55 \mathrm{kWh}$, respectively.

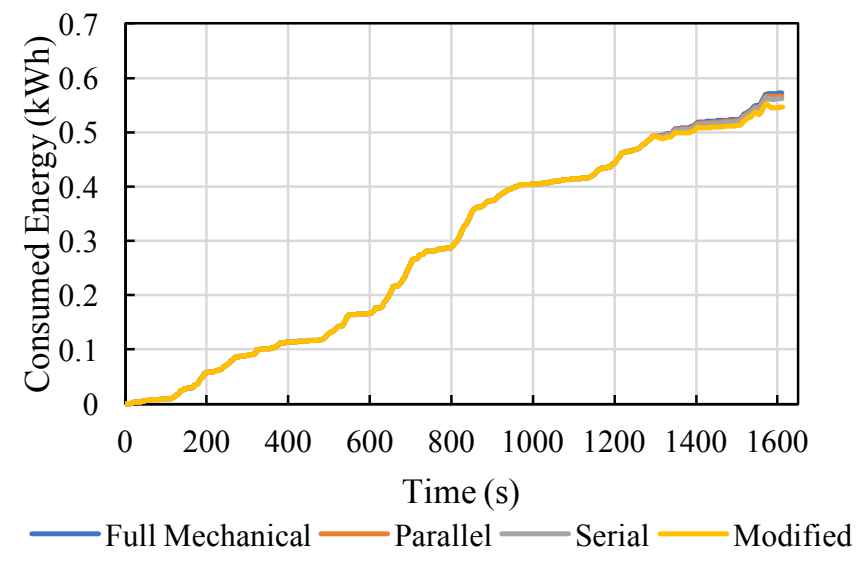

Figure 7 Energy consumption of one driving cycle with four braking strategies

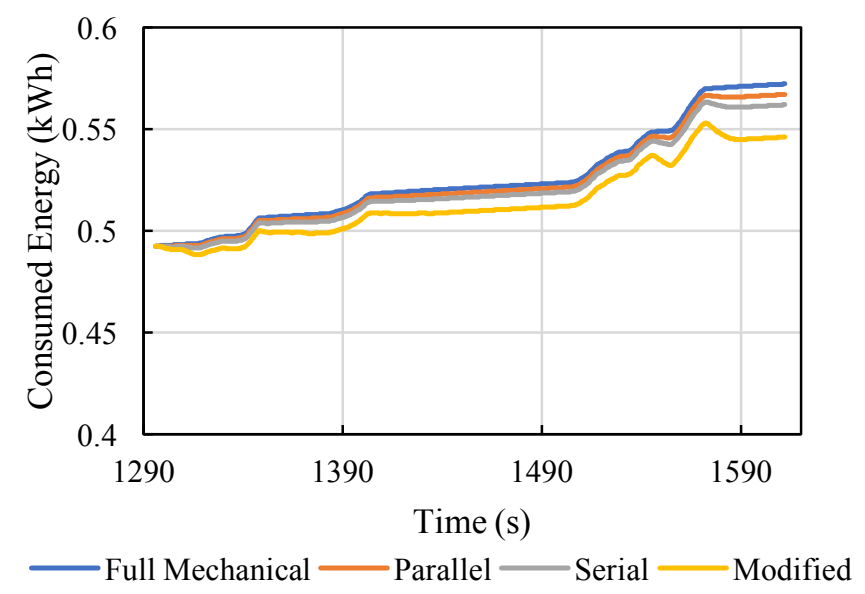

Figure 8 The difference in energy consumption of the four braking strategies
Table 4 Braking control system efficiency

\begin{tabular}{ccc}
\hline No & Braking System & $\mathbf{k m} / \mathbf{k W h}$ \\
\hline 1 & Full mechanical braking & 19.2 \\
2 & Parallel regenerative braking & 19.3 \\
3 & Serial regenerative braking & 19.5 \\
4 & Modified braking strategies & 20 \\
\hline
\end{tabular}

To find out the efficiency of each braking system, the value of consumed energy is compared with the total travel distance of one driving cycle into specific energy consumption. Table 4 shows the efficiency of each braking system. Knowing that the distance from one WLTP driving cycle is $10.97 \mathrm{~km}$, each efficiency of the braking system can be determined, which are 19.2 $\mathrm{km} / \mathrm{kWh}, 19.3 \mathrm{~km} / \mathrm{kWh}, 19.5 \mathrm{~km} / \mathrm{kWh}$, and 20 $\mathrm{km} / \mathrm{kWh}$.

\section{Conclusion}

Simulation results of the e-trike energy consumption using four different braking systems indicate that a modified braking system potentially makes significant energy saving. The efficiency of each braking system is then compared to achieve the highest efficiency. Full mechanical braking takes $19.2 \mathrm{~km} / \mathrm{kWh}$, whereas a modified braking strategy takes $20 \mathrm{~km} / \mathrm{kWh}$. Therefore, based on this comparison, the modified braking strategy appears to be the most efficient braking system compared to the others. Thus, the use of the modified braking strategy is strongly recommended to be implemented in the e-trike for better energy saving.

\section{Acknowledgment}

This research is funded by the Indonesian Endowment Fund for Education (LPDP) under RISPRO Research Grant No. PRJ-30/LPDP/2018.

\section{References}

[1] F. Arifurrahman, I. Indrawanto, B. A. Budiman, P. L. Sambegoro, and S. P. Santosa, "Frame modal analysis for an electric three-wheel vehicle," in Proceedings of MATEC Web of Conferences, vol. 197, p. 08001, Sept. 2018.

[2] F. Arifurrahman, B. A. Budiman, and S. P. Santosa, "Static Analysis of an Electric Three-Wheel Vehicle," in Proceedings of 5th International Conference on Electric Vehicular Technology (ICEVT), pp. 218-223, Oct. 2018.

[3] H. Ma, F. Balthasar, N. Tait, X. Riera-Palou, and A. Harrison, "A new comparison between the life cycle greenhouse gas emissions of battery electric vehicles and internal combustion vehicles," Energy Policy, vol. 44, pp. 160-173, Feb. 2012.

[4] C. C. Chan, "The state of the art of electric, hybrid, and fuel cell vehicles," in Proceedings of the IEEE, vol. 95, no. 4, pp. 704-718, April. 2007.

[5] P. Nyeste and M. S. Wogalter, "On adding sound to quiet vehicles," in Proceedings of the Human Factors and Ergonomics Society Annual Meeting, vol. 52, no. 21, pp. 1747-1750, California, United States of America, September, 2008. 
[6] J. Li and Z. Zhu, "Battery thermal management systems of electric vehicles," Chalmers University of Technology, Master's thesis, Göteborg, Sweden. 2014.

[7] P. N. Halimah, S. Rahardian, and B. A. Budiman, "Battery Cells for Electric Vehicles," International Journal of Sustainable Transportation Technology, vol. 2, no. 2, pp. 54-7, Oct. 2019.

[8] T. R. Jimenez, N. C. Ibarra, and J. M. Ramirez, "Main motor controllers and regenerative braking of an electric vehicle," in Proceedings of 2016 IEEE PES Transmission and Distribution Conference and Exposition-Latin America (PES T\&D-LA), pp. 1-6, Sept. 2016.

[9] M. Islameka, E. Leksono, and B. Yuliarto, "Modelling of regenerative braking system for electric bus," Journal of Physics: Conference Series, vol. 1402, no. 4, p. 044054, Dec. 2019.

[10] C. F. Kusuma, B. A. Budiman, and I. P. Nurprasetio, "Simulation Method for Extended-Range Electric Vehicle Battery State of Charge and Energy Consumption Simulation based on Driving Cycle," in Proceedings of 6th International Conference on Electric Vehicular Technology (ICEVT), pp. 336-344, Nov. 2019.

[11] J. D. Setiawan, B. A. Budiman, I. Haryanto, M. Munadi, M. Ariyanto, and M. A. Hidayat, "The Effect of Vehicle Inertia on Regenerative Braking Systems of Pure Electric Vehicles," in Proceedings of 6th International Conference on Electric Vehicular Technology (ICEVT), pp. 179-188, Nov. 2019

[12] P. Keil and A. Jossen, "Impact of dynamic driving loads and regenerative braking on the aging of lithium-ion batteries in electric vehicles," Journal of The Electrochemical Society, vol. 164, no. 13, pp. A3081-A3092, Oct. 2017.

[13] S. Heydari, P. Fajri, M. Rasheduzzaman, and R. Sabzehgar, "Maximizing regenerative braking energy recovery of electric vehicles through dynamic low-speed cutoff point detection," IEEE Transactions on Transportation Electrification, vol. 5, no. 1, pp. 262-270, Jan. 2019.

[14] M. Islameka, I. N. Haq, E. Leksono, and B. Yuliarto, "Energy Consumption Simulation and Analysis of RearDriven Electric Bus with Regenerative Braking," in Proceedings of 6th International Conference on Electric Vehicular Technology (ICEVT), pp. 105-110, Nov. 2019.

[15] J. Y. Wong. Theory of ground vehicles. Wiley, 2008.

[16] C. Lanczos. The variational principles of mechanics. Courier Corporation, 2012

[17] H. Steven, 2012. WLTP-DHC: WLTC cycles for validation 2 , based on the following preliminary vehicle classification [Online]. Available: http://www.unece.org/trans/main/wp29/wp29wgs/wp29grp e/wltp_dhc12.html. [Accessed: 28-Feb-2019].

[18] Z. Zhang, Y. Dong, and Y. Han, "Dynamic and control of electric vehicle in regenerative braking for driving safety and energy conservation," Journal of Vibration Engineering \& Technologies, pp.1-19, March. 2019.

[19] X. Cao and T. Ishikawa, "Optimum design of a regenerative braking system for electric vehicles based on fuzzy control strategy," IEEJ Transactions on Electrical and Electronic Engineering, vol. 11, pp. S186-S187. June. 2016. 